\title{
Validation of a New Paper-Tape Monitor for the Quasi-Continuous Determination of Airborne Diisocyanate Concentrations
}

\author{
Christian Monsé ${ }^{1^{*}}$, Jens-Uwe Hahn², Heinz Assenmacher-Maiworm², Gerd Keßler ${ }^{2}$, Jürgen Bünger ${ }^{1}$, Thomas Brüning ${ }^{1}$ and Rolf Merget ${ }^{1}$
}

${ }^{1}$ Institute for Prevention and Occupational Medicine of the German Social Accident Insurance, Institute of the Ruhr-University Bochum (IPA), Bürkle-de-la-Camp-Platz 1, 44789 Bochum, Germany

${ }^{2}$ Institute for Occupational Safety and Health of the German Social Accident Insurance (IFA), Alte Heerstr. 111, 53757 Sankt Augustin, Germany

\begin{abstract}
Occupational exposures to diisocyanates may cause allergic asthma. Inhalation challenges are the most important tool for the diagnosis of occupational asthma due to diisocyanates. Various diisocyanate atmospheres can be generated at IPA. A multi-steps exposure protocol is used, the dosage is constantly monitored and adjusted if necessary. The quasi-online monitoring of concentrations of airborne diisocyanates in the laboratory is done with a paper-tape monitor, which is widely used in laboratories that perform inhalation challenges worldwide, but also for monitoring of threshold limits at workplaces. The analyzer MDA 7100 (Zellweger Analytics, Inc., Lincolnshire, USA) is no longer supported by the producer. It was replaced by the successor model Single Point Monitor (Honeywell Analytics, Inc., Lincolnshire, USA), but comparative measurements are not available. It was the aim of this study to compare both paper-tape monitors with a discontinuous standard procedure.
\end{abstract}

Comparative measurements between the two paper-tape monitors showed that the newer model yielded lower concentrations than the old device. Both paper-tape monitors yielded lower values than the reference method at concentrations $>10 \mathrm{ppb}$. The old monitor detected $68 \%$, the new device $38 \%$ of the average concentration of the standard method at $36.7 \mathrm{ppb}$.

We conclude that the differences between the measurements with the new paper-tape monitor and the standard method are important above concentrations of about $10 \mathrm{ppb}$. For monitoring of diisocyanate concentrations $<5 \mathrm{ppb}$ at workplaces, the deviations are negligible.

Keywords: Diisocyanates; Paper-tape monitor; Reference method; Provocation test; Occupational asthma

\section{Introduction}

Exposures to airborne substances such as gases, vapors and particles may pose a health risk in many workplaces. Approximately $50 \%$ of all chemicals have a chemically irritant potential and can cause irritation, i.e. of eye or nose. There are also a number of substances which may cause sensitization or combine both features. Diisocyanates are widely used due to their broad spectrum of industrial applications (i.e. as lacquer or plastic industry). These substances can trigger immunologically mediated, allergic occupational asthma among workers. Affected persons develop symptoms after exposure to diisocyanates well below concentrations that remain without recognizable reactions in nonsensitized workers.

At the Institute for Prevention and Occupational Medicine of the German Social Accident Insurance (IPA) medical examinations are performed to answer the question whether a worker has developed an occupational allergy to these substances [1]. Inhalation challenges (subsequently referred to provocation tests) in the laboratory are an important tool in the diagnosis of immunologically mediated allergic occupational asthma [2]. In a recent consensus statement of the European Respiratory Society, this method is referred to as the "reference standard" for the diagnosis of allergic occupational asthma [3]. In the German guidelines [4] for the evaluation of obstructive airway diseases provocation tests are recommended if the causal relationship of medical history, symptoms and sensitization cannot be established with probability.

In order to perform standardized provocation tests, the respective atmospheres of these airborne substances must be generated in a precise way. A change in the dosage must be traceable. It must also be ensured that the composition of the gas phase is known. Decomposition processes can yield undesirable substances which are not covered either by measurement or appear unnoticed in a composite signal. Such substances may possibly trigger medical effect parameters in the patient, so that an assessment is difficult or impossible.

\section{Exposure laboratory and paper-tape-monitors}

Figure 1 shows the layout of the exposure laboratory, in which the provocation tests are performed. The dimensions of the room are $2 \mathrm{~m}$ $\mathrm{x} 3 \mathrm{~m}$. The laboratory has enough space for up to two subjects who are exposed simultaneously. A rack is installed below a ceiling fan with an evaporator system that generates the diisocyanate atmospheres in the laboratory. Two fans ensure homogeneous mixing of the atmospheres. Continuous air supply and discharge permit dynamic generation of airborne diisocyanates. Five diisocyanates can be used for assessments: methylene diisocyanate (MDI), hexamethylene diisocyanate (HDI), isophorone diisocyanate (IPDI), naphthalene-1,5-diisocyanate (NDI) and toluene-2,4-diisocyanate (TDI). It is decided on the basis of information of the patient's workplace, provided by the technical

*Corresponding author: Christian Monsé, Institute for Prevention and Occupationa Medicine of the German Social Accident Insurance, Institute of the Ruhr-University Bochum (IPA), Bürkle-de-la-Camp-Platz 1, 44789 Bochum, Germany, Tel: +49 (0)234 302-4521; Fax: +49 (0)234 302-4505; E-mail: monse@ipa-dguv.de

Received April 23, 2015; Accepted May 13, 2015; Published May 18, 2015

Citation: Monsé C, Hahn JU, Assenmacher-Maiworm H, Keßler G, Bünger J et al. (2015) Validation of a New Paper-Tape Monitor for the Quasi-Continuous Determination of Airborne Diisocyanate Concentrations. J Environ Anal Toxicol 5: 293. doi:10.4172/2161-0525.1000293

Copyright: (C) 2015 Monsé C, et al. This is an open-access article distributed under the terms of the Creative Commons Attribution License, which permits unrestricted use, distribution, and reproduction in any medium, provided the original author and source are credited. 
Citation: Monsé C, Hahn JU, Assenmacher-Maiworm H, Keßler G, Bünger J et al. (2015) Validation of a New Paper-Tape Monitor for the QuasiContinuous Determination of Airborne Diisocyanate Concentrations. J Environ Anal Toxicol 5: 293. doi:10.4172/2161-0525.1000293

Page 2 of 5

inspection service, with which substance the provocation test will be performed. A provocation test is performed only as a single exposure; mixtures of different diisocyanates are excluded due to the lack of metrological distinctness. As a rule, a patient is provoked only once.

The generation of MDI and NDI atmospheres is achieved by heating the substances that are in an open Petri dish. The various air concentrations are set on a hot plate at different temperatures. HDI, TDI and IPDI atmospheres are generated by heating the liquid substances in an Erlenmeyer flask in an oil bath. The diisocyanates are displaced with compressed air from the flask and the enriched air is conducted over a $2 \mathrm{~m}$ long Teflon tube (outer diameter $8 \mathrm{~mm}$, inner diameter 5 $\mathrm{mm}$ ) under the ceiling fan. By changes of temperature and compressed air stream, the concentrations can be varied. Previously the analyzer MDA 7100 (Zellweger Analytics; old device) was used to control the target concentrations. However, this device is no longer repaired nor maintained by the manufacturer. It was replaced by the successor model Single Point Monitor (Honeywell; new device). The two paper-tape monitors of different generations have identical detection methods. The measuring principle is based on a color reaction of a specially impregnated filter material through which the atmosphere of laboratory air is pumped at a constant flow rate. The intensity of the color is proportional to the concentration of airborne isocyanate groups (NCO), regardless of whether the analyte is a 2-core or multicore isocyanate or a NCO-containing urea derivative (sum parameter $\mathrm{NCO}$ ). The measurement time is, depending on the diisocyanate, 2 to 3 minutes and is predetermined by the manufacturer. The measuring cell is supplied with fresh filter material before the measurements. It can be assumed that the measurement frequencies represent a quasicontinuous control of the test atmospheres. The measurement method is often used for the monitoring of diisocyanate exposure limits at workplaces. It is characterized by the rapid measurement time, but not suitable for certain job conditions i.e. presence of diisocyanatecontaining aerosols [5].

Until March 2014, provocation tests were performed according to the exposure protocol A, shown in Figure 2. The patient was exposed to diisocyanate concentrations between 3-20 ppb. Prior to the test, during breaks and in a follow-up phase (scheme not shown), lung function measurements were performed in order to demonstrate a possible allergic asthmatic reaction.

\section{Comparison of measurements}

A discontinuous measurement method was used for validation (reference method of the Institute for Occupational Safety and Health of the German Social Accident Insurance (IFA)). All measurements were carried out with the most commonly used diisocyanates MDI and HDI for the diagnosis of occupational asthma at IPA. Air sampling was performed with 1- (2-methoxyphenyl) piperazine-impregnated glass fiber filters. After preparation of the samples, the analysis was realized by LC-MS [6].

We performed two series of measurements with MDI (March 2013 - measurement series 1 and November 2013 - measurement series 2) and three sets of measurements with HDI (March 2013 - measurement series 1, November 2013 - measurement series 2 and July 2014 measurement series 3). In March 2013, comparative measurements were performed between the old device and the IFA reference method, in November 2013 between old device, new device and IFA method - and in July 2014 between new device and IFA method.
Sampling for the reference was carried out at three measuring points: Near the hot plate (Figure 1, measuring point 1), at the detector input (Point 2) and at the subjects chair (Point 3). The sampling time of the respective measurement series in March 2013 was 30 minutes, the time for all other measurements was 20 minutes. Technical MDI (mixture of di- and tri-isocyanates for synthesis, Merck $\mathrm{GmbH}$, Darmstadt, Germany) and monomeric HDI (Merck) were used for the measurements [7].

\section{Results}

\section{MDI measurement series 1 and 2:}

An LC-MS analysis of the non-vaporized material sample showed 2,2'-, 2,4'- and 4,4'-MDI and 3-, 4- and 5-core MDI (Figure 3).

In all air samples no 3-, 4- and 5-core MDI were found, as expected due to the high molecular weights and low vapor pressures, respectively. The average composition of the gas phase was determined by the reference method to $1.7 \%$ of 2,2'-MDI, $16.4 \% 2,4^{\prime}-$ MDI and $81.8 \% 4,4$ '-MDI. LC-MS analysis identified MDI urea dimers and trimers (Figures 4 and 5) at temperatures of $132^{\circ} \mathrm{C}$ (corresponding to a concentration of $5 \mathrm{ppb}$ indicated by the old device).

The determined concentration of the urea compounds by LC-MS analysis was $4.3 \mathrm{ppb}$ (at the highest MDI concentration of $51.7 \mathrm{ppb}$ averaged over the three measuring points), whereas at a total MDI concentration of $36.7 \mathrm{ppb}$, the concentration of the urea compounds was $2.0 \mathrm{ppb}$. Under all other conditions the concentrations were dependent on the particular sampling time and were below the detection limit of 0.5 and $0.3 \mathrm{ppb}$, respectively (Tables 1 and 2).

The measured values of the measuring points 1 to 3 shown in Tables 1 and 2, as determined by the reference method show the sum of concentrations of 2,2'-, 2,4'- and 4,4'-MDI isomers. As can be seen from the tables, the concentrations of the reference method are higher

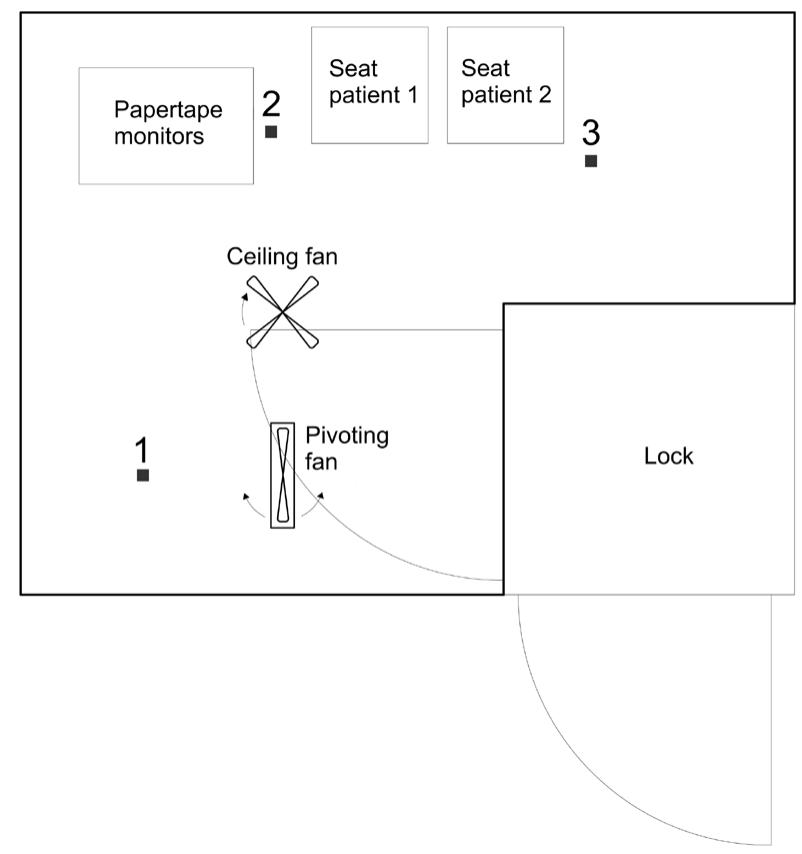

Figure 1: Layout of the exposure laboratory. 1, 2, 3: measurement points. 
Citation: Monsé C, Hahn JU, Assenmacher-Maiworm H, Keßler G, Bünger J et al. (2015) Validation of a New Paper-Tape Monitor for the QuasiContinuous Determination of Airborne Diisocyanate Concentrations. J Environ Anal Toxicol 5: 293. doi:10.4172/2161-0525.1000293

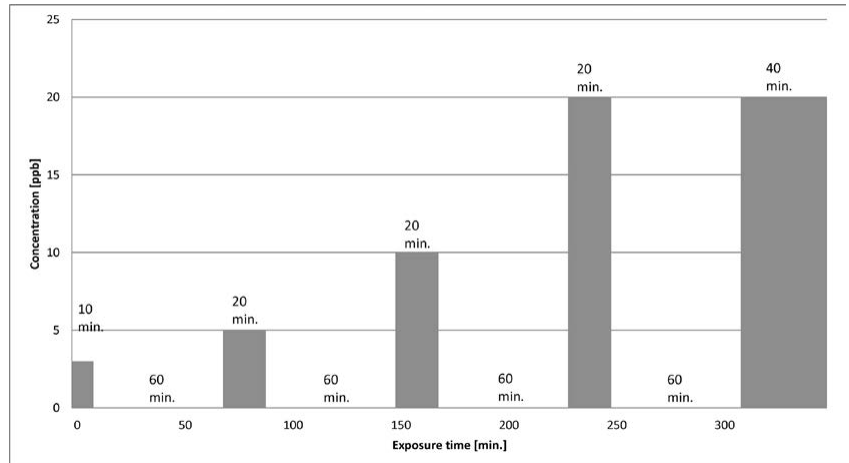

Figure 2: Exposure Protocol A before March 2014.

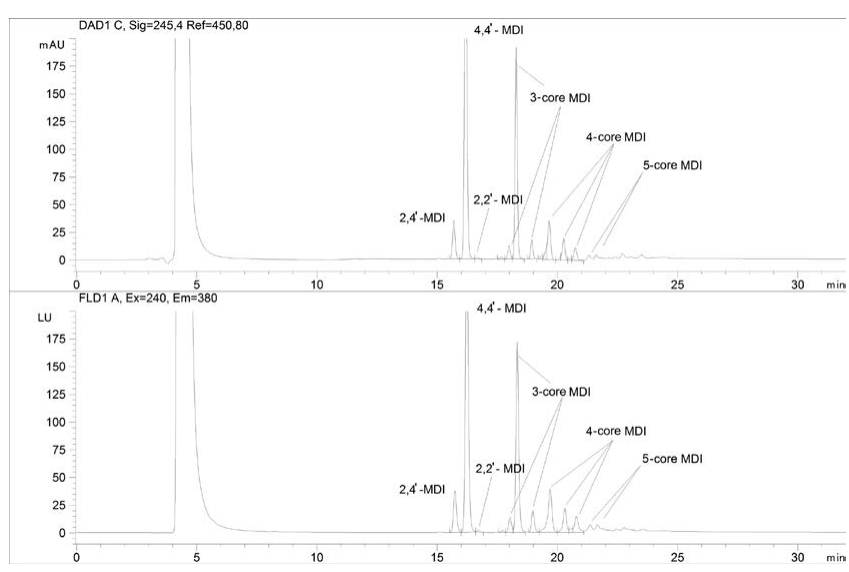

Figure 3: Chromatogram of a technical MDI.

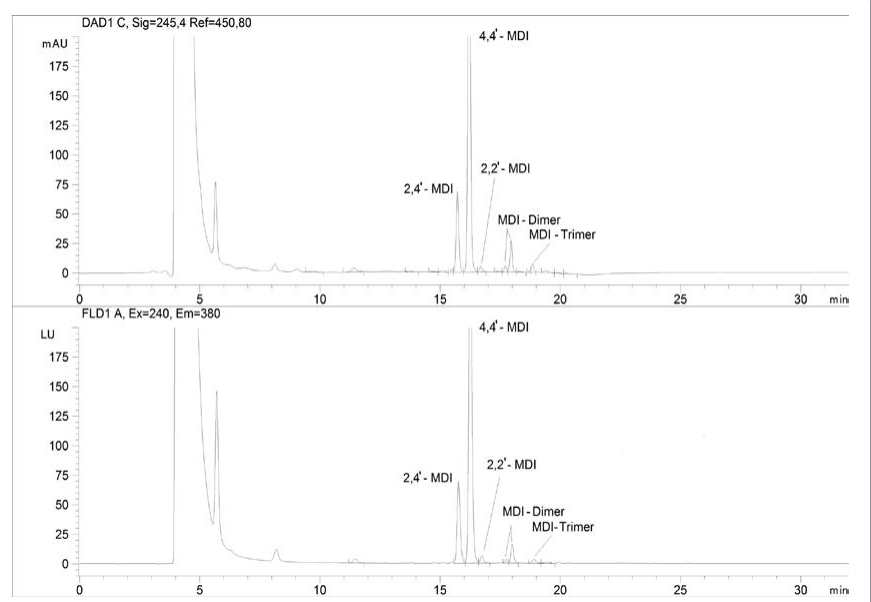

Figure 4: Chromatogram of an air sample of MDI - Measurement series 1, Point 3.

by a factor of 1.5 than the levels indicated by the old device. The new device (Table 2) still delivers lower readings, particularly at the highest concentration (36.7 ppb). While the old device detected even $68 \%$, the new device showed only $38 \%$ of the reference method. To exclude a device error of the new device we lent a second Single Point Monitor from Honeywell Analytics, Inc. Comparison of results under repeated experimental conditions yielded near identical results (data not shown).

\section{HDI measurement series 1,2 and 3 :}

The measurement results are summarized in Tables 3-5. Figure 6 shows the chromatogram of the experiment at $16 \mathrm{ppb}$, displayed on the new device (HDI measurement series 3 ).

The results are similar to those of the MDI measurements. Again, it can be observed that the HDI concentrations measured with the reference method are higher than those measured with the paper-tape monitors. On average, the measured values of the reference method are higher by a factor of $1.2-1.4$. Figure 7 shows the HDI and MDI concentration profiles of both paper-tape monitors and the reference method, compiled from the MDI measurement series 2 and the HDI measurement series 2 .

In Tables 3 and 4 the HDI concentrations suggest that there could be problems with the homogeneous distribution in the exposure laboratory atmosphere. In July 2014 final measurements were carried out for clarification. The difference between the HDI measurement series 3 and series 1 and 2 was that the HDI-burdened air was now passed out of the Teflon tube of the evaporator system directly into the ceiling fan. Previously, the distance between the tube output and ventilator was about $30 \mathrm{~cm}$. As can be seen from Table 5, the measurement points 1-3 showed smaller deviations, indicating an improved homogeneity of the gas phase.

\section{Discussion}

The most important finding of this study is that the new device indicated too low values at increasing diisocyanate concentrations. Presumably, the measurement range is much smaller than in the specification of the manufacturer that defines a range of 2- $60 \mathrm{ppb}$. Overall, both paper-tape monitors yield too low concentrations in comparison with the reference method. Since the concentration differences between the new device and the reference method drift further apart at higher concentrations, our exposure protocol A (Figure 2), which was used until March 2014, was adjusted for the assessment of diisocyanate triggered asthma; now we use the exposure protocol $\mathrm{B}$ (Figure 8). The highest diisocyanate concentration level of $20 \mathrm{ppb}$ was lowered to $10 \mathrm{ppb}$ in the exposure protocol B, because diisocyanate concentrations above $10 \mathrm{ppb}$ cannot be measured reliably. Further studies should be performed to assure that the sensitivity of provocation testing will not decrease after lowering the maximal concentration to half of the previously administered concentration. As the administered dose is the most important determinant of the allergic reaction [8],<smiles></smiles><smiles></smiles>

Figure 5: Structures of 4,4'-MDI urea dimer and 4,4'-MDI urea trimer. 
Citation: Monsé C, Hahn JU, Assenmacher-Maiworm H, Keßler G, Bünger J et al. (2015) Validation of a New Paper-Tape Monitor for the QuasiContinuous Determination of Airborne Diisocyanate Concentrations. J Environ Anal Toxicol 5: 293. doi:10.4172/2161-0525.1000293

Page 4 of 5

\begin{tabular}{|c|c|c|c|c|c|}
\hline \multirow{2}{*}{ Diisocyanate } & $\begin{array}{c}\text { Paper-tape } \\
\text { monitor }\end{array}$ & \multicolumn{2}{|c|}{} & \multicolumn{2}{|c|}{ IFA reference method } \\
\cline { 2 - 6 } & $\begin{array}{c}\text { Old } \\
\text { device }\end{array}$ & $\begin{array}{c}\text { Measurement } \\
\text { point 1 }\end{array}$ & $\begin{array}{c}\text { Measurement } \\
\text { point 2 }\end{array}$ & $\begin{array}{c}\text { Measurement } \\
\text { point 3 }\end{array}$ & Average \\
\hline MDI & $\mathbf{5}$ & 9.1 & 7.8 & 7.5 & 16.0 \\
\hline MDI & $\mathbf{1 0}$ & 18.0 & 16.0 & 49.0 \\
\hline
\end{tabular}

Table 1: MDI measurement series 1, March 2013, concentrations in [ppb].

\begin{tabular}{|c|c|c|c|c|c|}
\hline \multirow{2}{*}{ Diisocyanate } & Paper-tape monitors & & \multicolumn{2}{|c|}{ IFA reference method } \\
\cline { 2 - 6 } & $\begin{array}{c}\text { New } \\
\text { device }\end{array}$ & $\begin{array}{c}\text { Old } \\
\text { device }\end{array}$ & Measurement point 1 & Measurement point 2 & Measurement point 3 \\
\hline MDI & $\mathbf{4}$ & $\mathbf{4}$ & 6.0 & 5.0 & 5.0 \\
\hline $\mathrm{MDI}$ & $\mathbf{6}$ & $\mathbf{7}$ & 12.0 & 10.0 & 10.0 \\
\hline $\mathrm{MDI}$ & $\mathbf{1 4}$ & $\mathbf{2 5}$ & 3.0 & 37.0 & 35.0 \\
\hline
\end{tabular}

Table 2: MDI measurement series 2, November 2013, concentrations in [ppb].

\begin{tabular}{|c|c|c|c|c|c|}
\hline \multirow{2}{*}{ Diisocyanate } & $\begin{array}{c}\text { Paper-tape } \\
\text { monitor }\end{array}$ & \multicolumn{4}{|c|}{ IFA reference method } \\
\cline { 2 - 6 } & $\begin{array}{c}\text { Old } \\
\text { device }\end{array}$ & $\begin{array}{c}\text { Measurement } \\
\text { point 1 }\end{array}$ & $\begin{array}{c}\text { Measurement } \\
\text { point 2 }\end{array}$ & $\begin{array}{c}\text { Measurement } \\
\text { point 3 }\end{array}$ & Average \\
\hline HDI & $\mathbf{1 2}$ & $22.0^{*}$ & 14.0 & 14.0 & $\mathbf{1 4 . 0}$ \\
\hline HDI & $\mathbf{2 5}$ & $55.0^{*}$ & 33.0 & 33.0 & \\
\hline
\end{tabular}

Marked values with * were excluded in the averaging.

Table 3: HDI measurement series 1, March 2013, concentrations in [ppb].

\begin{tabular}{|c|c|c|c|c|c|c|}
\hline \multirow[t]{2}{*}{ Diisocyanate } & \multicolumn{2}{|c|}{$\begin{array}{l}\text { Paper-tape } \\
\text { monitors }\end{array}$} & \multicolumn{4}{|c|}{ IFA reference method } \\
\hline & $\begin{array}{c}\text { New } \\
\text { device }\end{array}$ & $\begin{array}{c}\text { Old } \\
\text { device }\end{array}$ & $\begin{array}{l}\text { Measurement } \\
\text { point } 1\end{array}$ & $\begin{array}{l}\text { Measurement } \\
\text { point } 2\end{array}$ & $\begin{array}{l}\text { Measurement } \\
\text { point } 3\end{array}$ & Average \\
\hline HDI & 8 & 8 & $16^{*}$ & 10.0 & 10.0 & 10.0 \\
\hline HDI & 18 & 20 & $39^{*}$ & 29.0 & 19.0 & 24.0 \\
\hline
\end{tabular}

Marked values with * were excluded in the averaging.

Table 4: HDI measurement series 2, November 2013, concentrations in [ppb].

\begin{tabular}{|c|c|c|c|c|c|}
\hline \multirow{2}{*}{ Diisocyanate } & Paper-tape monitor & \multicolumn{2}{|c|}{ IFA reference method } \\
\cline { 2 - 5 } & $\begin{array}{c}\text { New } \\
\text { device }\end{array}$ & Measurement point 1 & Measurement point 2 & Measurement point 3 & Average \\
\hline HDI & $\mathbf{2}$ & 3.0 & 3.0 & 3.0 \\
\hline HDI & $\mathbf{9}$ & 12.0 & 11.0 & 12.0 \\
\hline HDI & $\mathbf{1 6}$ & 19.0 & 21.0 & $\mathbf{3 . 0}$ \\
\hline
\end{tabular}

Table 5: HDI measurement series 3, July 2014, concentrations in [ppb].

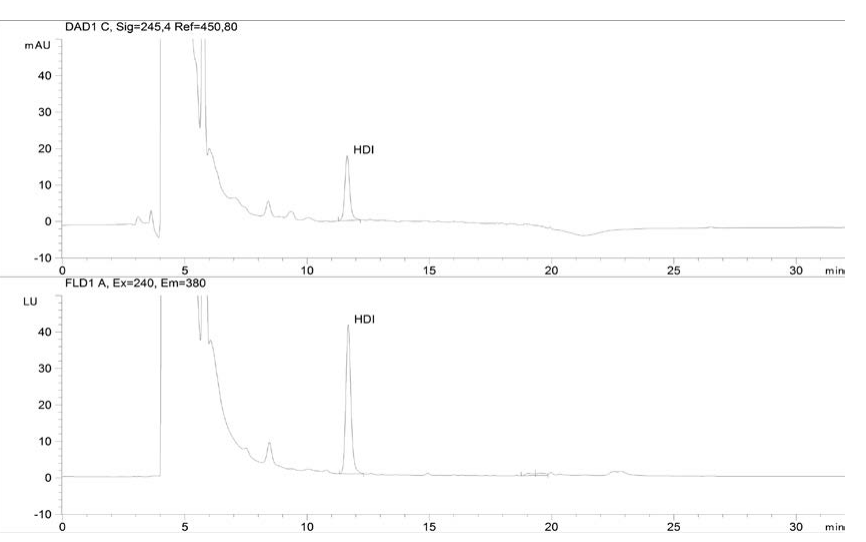

Figure 6: Chromatogram of an air sample of HDI - Measurement series 3, Point 3. maintaining the dose of the previous protocol would result in too long exposure durations.

As can be seen in Figure 7, the differences between the two methods of measurements up to $10 \mathrm{ppb}$ are acceptable. Up to this concentration the displayed concentrations by the new device can be adapted to the reference method with an appropriate correction factor. If concentrations $>10 \mathrm{ppb}$ have to be measured, the application of a correction factor is not recommended due to an increasing and quantitatively uncertain underestimation with increasing diisocyanate concentrations.

At the same time it is ensured that only small amounts of urea compounds are generated during the evaporation process of technical MDI by lowering the maximal concentration. It is unknown whether these compounds could have medical effects at higher concentrations. The measured deviations between methods in the range of up to $5 \mathrm{ppb}$ are negligibly small, so that the new device is suitable for monitoring 
Citation: Monsé C, Hahn JU, Assenmacher-Maiworm H, Keßler G, Bünger J et al. (2015) Validation of a New Paper-Tape Monitor for the QuasiContinuous Determination of Airborne Diisocyanate Concentrations. J Environ Anal Toxicol 5: 293. doi:10.4172/2161-0525.1000293

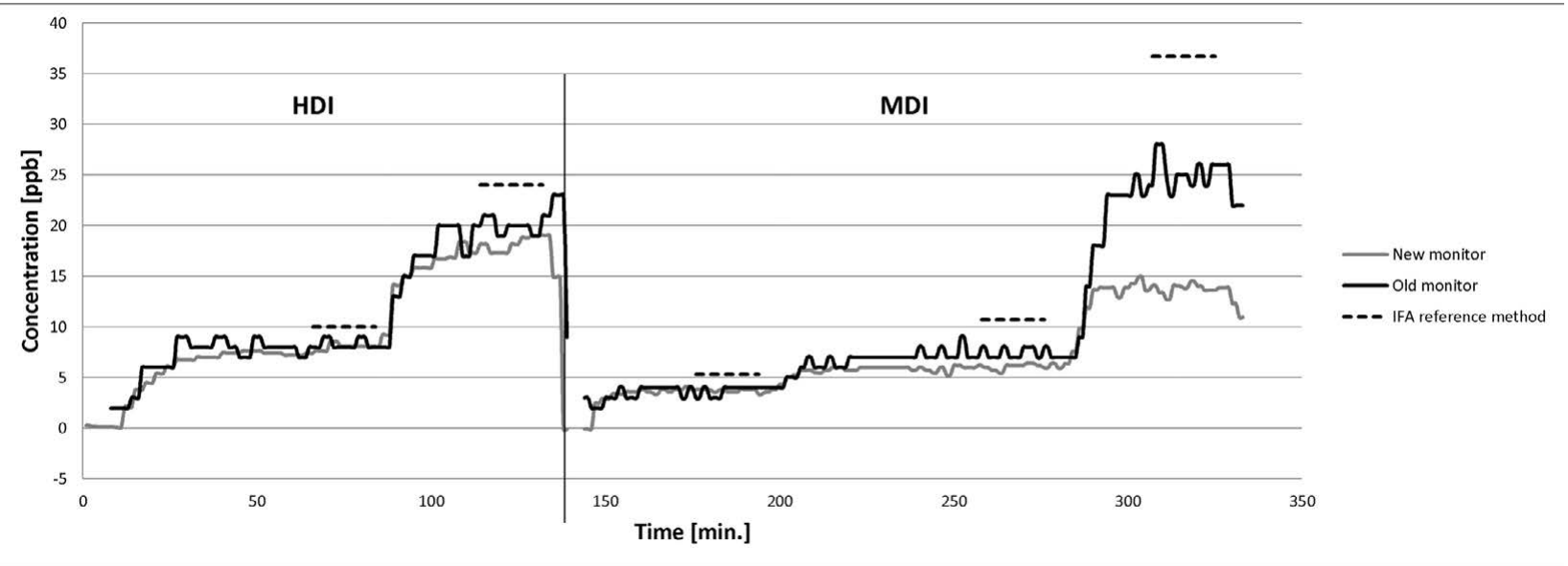

Figure 7: Concentration curves compared between old device, new device and reference method.

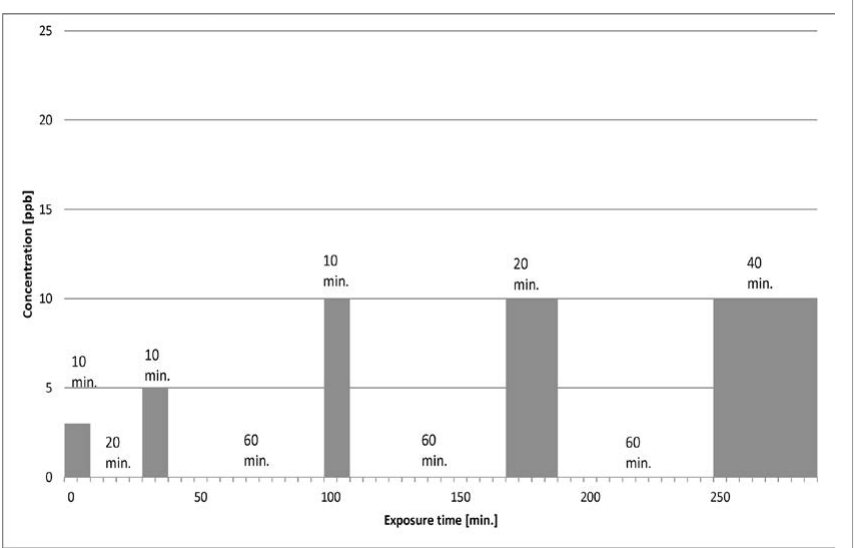

Figure 8: Adjusted exposure protocol B from March 2014.

the compliance of occupational exposure limit values.

A secondary finding was the improved homogeneity of HDI containing atmospheres by passing the high concentrated HDIburdened air out of the Teflon tube of the evaporator system directly into the ceiling fan in the laboratory. In contrast to the old procedure HDI can now be better distributed by fast mixing of high concentrated airborne HDI with the laboratory air to yield a target concentration. As a conclusion we will perform future provocation tests in the same way not only for HDI- but also for IPDI- and TDI- assessments.

\section{References}

1. Scheidler L, Sucker K, Taeger D, van Kampen V, Heinze E, et al. (2013) Evaluation of a 4-steps-1-day whole body challenge protocol for the diagnosis of occupational asthma due to diisocyanates. Adv Exp Med Biol 788: 301-311.

2. Tarlo SM, Balmes J, Balkissoon R, Beach J, Beckett W, et al. (2008) Diagnosis and management of work-related asthma: American College Of Chest Physicians Consensus Statement. Chest 134: 1S-41S.

3. Vandenplas O, Suojalehto H, Aasen TB, Baur X, Burge PS, et al. (2014) Specific inhalation challenge in the diagnosis of occupational asthma: consensus statement. Eur Respir J 43: 1573-1587.

4. Empfehlung für die Begutachtung der Berufskrankheiten der Nummern 1315 (ohne Alveolitis), 4301 und 4302 der Anlage zur Berufskrankheiten-Verordnung (BKV), Hrsg. Deutsche Gesetzliche Unfallversicherung e. V. (DGUV), 2012.

5. Brandt B, Assenmacher-Maiworm H, Hahn J-U (2013) Messung und Beurteilung von Isocyanaten an Arbeitsplätzen unter Beachtung der TRGS 430. Gefahrst Reinhalt L 73: 209-218.

6. Hahn JU, Assenmacher-Maiworm H (2009) Isocyanate Kennziffer 7670 in Messung von Gefahrstoffen - IFA-Arbeitsmappe, Gefährdungsermittlung bei chemischen und biologischen Einwirkungen. Loseblattwerk, seit 1989, Herausgeber: Deutsche Gesetzliche Unfallversicherung.

7. Meister EF, Brusis T (2013) [From the expert's office: The Reichenhaller Empfehlung of 2012-essentiell alterations and modifications]. Laryngorhinootologie 92: 761-762.

8. Vandenplas O, Cartier A, Ghezzo H, Cloutier Y, Malo JL (1993) Response to isocyanates: effect of concentration, duration of exposure, and dose. Am Rev Respir Dis 147: 1287-1290. 